\title{
Cultural competence of Australian dental students
}

\author{
Rodrigo Mariño ${ }^{*}$, Julie Satur, Eren Tuncer, Megan Tran, Elizabeth Milford, Vivien Minh Thien Huong Tran, \\ Phuong Qui Tran and Richard Pei-Hua Tsai
}

\begin{abstract}
Background: Australia possesses a highly multicultural demographic, and thus dental practitioners are likely to regularly encounter culturally and linguistically diverse individuals. It is important for dental practitioners to be culturally competent, however, cultural competency education is highly variable in the curricula of dentistry and oral health courses in Australia, and research is largely limited to dentistry students. This study aims to investigate and compare perceived attitudes, beliefs and practices of cultural competence amongst first and final year Doctor of Dental Surgery (DDS) and Bachelor of Oral Health (BOH) students at the University of Melbourne Dental School.
\end{abstract}

Methods: Following ethics approval, anonymous questionnaires were completed by 213 participants. The questionnaire was adapted from Schwarz's Healthcare Provider Cultural Competence Instrument and consisted of five scales. Data was analysed using SPSS V 24.0 software.

Results: A total of 213 students participated in this study (response rate $=88 \%$ ) The majority of participants were female $(n=114,53.5 \%)$ and the mean age of 23.5 years (range 18-40). The majority of participants were Australian born $(n=110)$ with $74.6 \%(n=159)$ first generation Australians. Participants who identified as Australian represented $35.7 \%(n=76)$ with $66.1 \%(n=141)$ identified as partly Australian. Multivariate analysis indicated that, after controlling for other independent variables in the model, those who had the highest cultural competence score were female, who self-identify as "Australian", who were in the final year. Furthermore, those who were in the final $\mathrm{BOH}$ year scored significatively higher than final year DDS students.

Conclusion: The findings of this study suggest that there is a significant difference in students self-reported cultural competence at different stages of their education. This may be attributed to differences in cultural competence education, scope of practice and the type of patient encounters and role modelling that students may experience. Future research should involve follow up to create longitudinal data, as well as research at other dental schools in Australia and overseas.

Keywords: Cultural competence, Dental students, Oral health

\section{Background}

An estimated $28.2 \%$ of the current Australian population was born overseas. Australia is a federation with six states. Victoria is the second largest state by population (i.e., 6.3 million), and the fastest growing in the nation, with a $1.9 \%$ increase in annual migration from overseas [1]. It is well

\footnotetext{
* Correspondence: r.marino@unimelb.edu.au
}

Melbourne Dental School, University of Melbourne, Melbourne, Australia established that cultural minorities and immigrant populations are disproportionately affected by a wide variety of general health and oral health conditions [2]. Therefore, an oral health care professional is highly likely to encounter individuals from a variety of cultural backgrounds on a daily basis during his/her professional life [3-9]. Each culture has unique beliefs, practices, and expectations of

(c) The Author(s). 2021 Open Access This article is licensed under a Creative Commons Attribution 4.0 International License, which permits use, sharing, adaptation, distribution and reproduction in any medium or format, as long as you give appropriate credit to the original author(s) and the source, provide a link to the Creative Commons licence, and indicate if changes were made. The images or other third party material in this article are included in the article's Creative Commons licence, unless indicated otherwise in a credit line to the material. If material is not included in the article's Creative Commons licence and your intended use is not permitted by statutory regulation or exceeds the permitted use, you will need to obtain permission directly from the copyright holder. To view a copy of this licence, visit http://creativecommons.org/licenses/by/4.0/ The Creative Commons Public Domain Dedication waiver (http://creativecommons.org/publicdomain/zero/1.0/) applies to the data made available in this article, unless otherwise stated in a credit line to the data. 
oral health care, rendering cultural competence of great importance to dental practitioners.

Underlying cultural beliefs and practices influence the condition of the teeth and mouth, through diet, care-seeking behaviors, or use of home remedies. Individuals from different cultural groups may have oral habits that seem unusual in Western culture. For example, oral hygiene practices (e.g., use of miswak), the habit of chewing betel nut quid, which can damage to the oral mucosa, including the possibility of pre-cancerous or cancerous lesions; tooth lacquering, to name a few $[10,11]$. There are also culture influences on expectations, communication and behavior during patient/dental practitioner interactions, which may impact the effectiveness and quality of care.

Therefore, the acquisition and development of cultural competence should begin during a student dental practitioner's education $[8,12]$. With Australia being one of the most culturally diverse countries in the world, it is essential to have culturally competent oral health care professionals in order to address oral health care disparity amongst new immigrant populations as well as supporting interactions with patients from a variety of cultural backgrounds.

Cultural competence amongst health practitioners has been defined in academic literature, as well as in guidelines, policies and standards compiled by the relevant government, health and education bodies worldwide. Betancourt and collaborators [13] define cultural competency in health care as an "understanding [of] the importance of social and cultural influences on patients' health beliefs and behaviours; considering how these factors interact at multiple levels of the health care delivery system... [and] devising interventions that take these issues into account to assure quality health care delivery to diverse populations."

Healthcare bodies have adopted such definitions into their relevant policies, albeit in a more concise and simplified form. The Dental Board of Australia's Code of Conduct outlines the importance of "culturally safe and sensitive practice" [14], acknowledging that differences in the cultural background of both practitioners and patients can influence interactions. Such awareness enables practitioners to adapt appropriately in order to provide good health outcomes [14]. Furthermore, The Australian Dental Council's (ADC) competency standards used in accreditation of dental education programs require that cultural safety is integrated within the programs to ensure that" students are able to provide culturally safe care for Aboriginal and Torres Strait Islander Peoples." [15]. This is supported by the University through the valuing of diversity, inclusion and respect for the history and lived experiences and culture of staff, students and the communities they serve [16].
Informed by Betancourt and collaborators' [13], definition, Schwarz and collaborators [17] describe a model which acknowledges an inherent interaction between cultural awareness and sensitivity, patientcentred communication, and patient centred care orientation, acknowledging the attitudes of health care professionals towards patients and their healthcare experience. In addition, this definition assumes that culturally competent individuals possess knowledge about different languages, beliefs, customs, practices and worldviews.

The teaching of cultural competency skills in dental courses has been assessed. Around the world, dental schools have reported cultural competency as a core component of the dental professional curricula. Some schools have included a devoted subject or have integrated cultural competency into other educational experiences, such as in clinical rotations in North America $[18,19]$. In Australia and New Zealand, Nicholson and collaborators [9] survey of various dentistry, dental hygiene and oral health therapy courses across Australia and New Zealand demonstrated that almost all courses incorporated one or more elements.

Strauss and collaborators [20], in North American and Nicholson and collaborators [9] in Australia and New Zealand, observed that dental schools favoured learning techniques such as lectures as the most frequently used teaching method of cultural competency, followed by discussion, self-directed learning, group work and workshops. Mariño and collaborators [21] and Wagner and collaborators [22] also identified that elements of cultural competency were incorporated into other aspects of the dental course curricula, such as clinical placements and work integrated learning. In addition to conventional training, there is evidence that dental students benefit from interactive learning opportunities to effectively improve their self-efficacy and cultural competence, with $80 \%$ of students indicating feeling more comfortable working with people of diverse backgrounds following these experiences [23].

Forsyth and collaborators [24] devised a model highlighting the need for cultural competence to be incorporated into university strategic plans at universitywide, faculty, and school levels, to ensure students achieve a minimum level of cultural competency upon graduation. Although this was devised for Indigenous cultural competence in dentistry, the model may apply to general cultural competence for all medicine and health curricula. Attention to this as an important strategic direction for the school, faculty and university has been articulated through both structural and policy approaches in recent years $[16,25,26]$.

Clinical supervisors, when surveyed said that the current curricula and examinations of both Doctor of Dental Surgery (DDS) and Bachelor of Oral Health 
$(\mathrm{BOH})$ students at the University of Melbourne Dental School (UoMDS) did not focus enough on cultural issues and that additional training would be beneficial, especially in areas of patient management and rapport building [19]. Supervisors suggested that cultural competence should be a recurring theme throughout the courses each year, rather than limited to clinical placements. This would enable dental students to communicate more effectively with patients [5]. This view is supported by a recent systematic review finding that a combination of didactic/ online training, community engagement, and reflective writing increased cultural competence of dental students [27].

In order to gain a broader understanding of how dental students' cultural competency is influenced by educational programs as they progress through their oral health training, this study aims to investigate perceived attitudes, beliefs and practices of cultural competence amongst first and final year DDS and $\mathrm{BOH}$ students at UoMDS. This will be explored via the students' selfperception of their individual cultural competency. These perceptions of cultural competence, for each respective course may reflect how successful the current curricula are in delivering culturally competent education and may inform future improvements to fulfil student needs.

\section{Methods}

Following ethics approval (ID:1749059.2) the study surveyed UoMDS first and final year $\mathrm{BOH}$ (BOH1 and $\mathrm{BOH} 3$, respectively) students and first and final year DDS (DDS1 and DDS4, respectively) students using anonymous self-completed questionnaires adapted from Schwarz's Healthcare Provider Cultural Competence Instrument (HPCCI) [14]. Adaptations were introduced to provide an Australian context and a focus on oral healthcare (e.g., "Language barriers are the only difficulties for recent immigrants to Australia"; "I find it difficult to manage cultural issues as well as clinical issues when providing oral health care").

The selection of such cohorts allows the possibility to examine the effect of time in the development of cultural competence amongst specific students over time. However, the present approach was one of cross-sectional measurements of different cohorts. The approach allowed sampling to take snapshots in time to review the cultural competency of new (i.e., BOH1 and DDS1 cohorts) and existing students (i.e., BOH3 and DDS4 cohorts). This permitted an assessment of what cultural competencies the students have in their initial year, and then the overall cultural competencies of those who are in their final year of the programmes (which would be influenced by the curriculum as well as possible external factors). Thus, different samples were used each year.

The HPCCI is comprised of five scales: Awareness and sensitivity (10 items), Cultural competence behaviours (11 items), Patient-centred communication (4 items), Practice orientation (10 items), and Self-assessment of cultural competence (8 items). Responses were recorded on a 5-point Likert scale from 'Strongly agree' to 'Strongly disagree'. The questionnaire also sought information about participant demographics and cultural background.

From the HPCCI [15], items were selected and adjusted to be specifically relevant to the dental professions and applicable to students as opposed to qualified professionals. Data were collected using a paper survey distributed to invited student cohorts at the beginning of appropriate class times, which were subsequently collected upon completion by researchers.

There were two versions of the questionnaire. One consisting of 24 questions that was distributed to the first-year cohorts, and another comprised of 43 questions that was distributed to final year cohorts (Table 1). Questions omitted from the first-year students' survey included all those items enquiring about practice orientation and patient-centred communication, as well as five items about cultural competence behaviours, as it was determined that such questions could not be accurately answered by an individual without clinical experience. Data were collected during the 2018 academic year. The final year cohorts (DDS4 and BOH3) data was collected around April, approximately mid-way through their final academic year. For the DDS1 first-year cohort data was collected in February, but for the BOH1 cohort be data was collected on what it would the end of their first academic year.

A power analysis determined that a sample size of 26 participants in each group would yield a power of .80 at a significance level of 0.05 with an estimated effect size between medium and large. Reliability and validity of the revised HPCCI instrument was reviewed. Cronbach's alpha was used to determine the internal consistency. The reliabilities of the five scales were found to be in the range of 0.79 to 0.99 . Construct validity of the scale was assessed through a factor-analysis of the instrument's 43 items using the maximum-likelihood estimation method with oblique rotation. The analysis indicated that the factor structure of the revised HPCCI approximated the five dimensions of the original instrument [28].

The analysis included the dependent variables represented by the five cultural competence scales scores and seven independent variables. Five cultural competence scores were computed by adding the responses across each of the five cultural competence items. Additionally, in order to quantify all responses, an overall cultural 
Table 1 Healthcare Provider Cultural Competence Instrument (HPCCI)

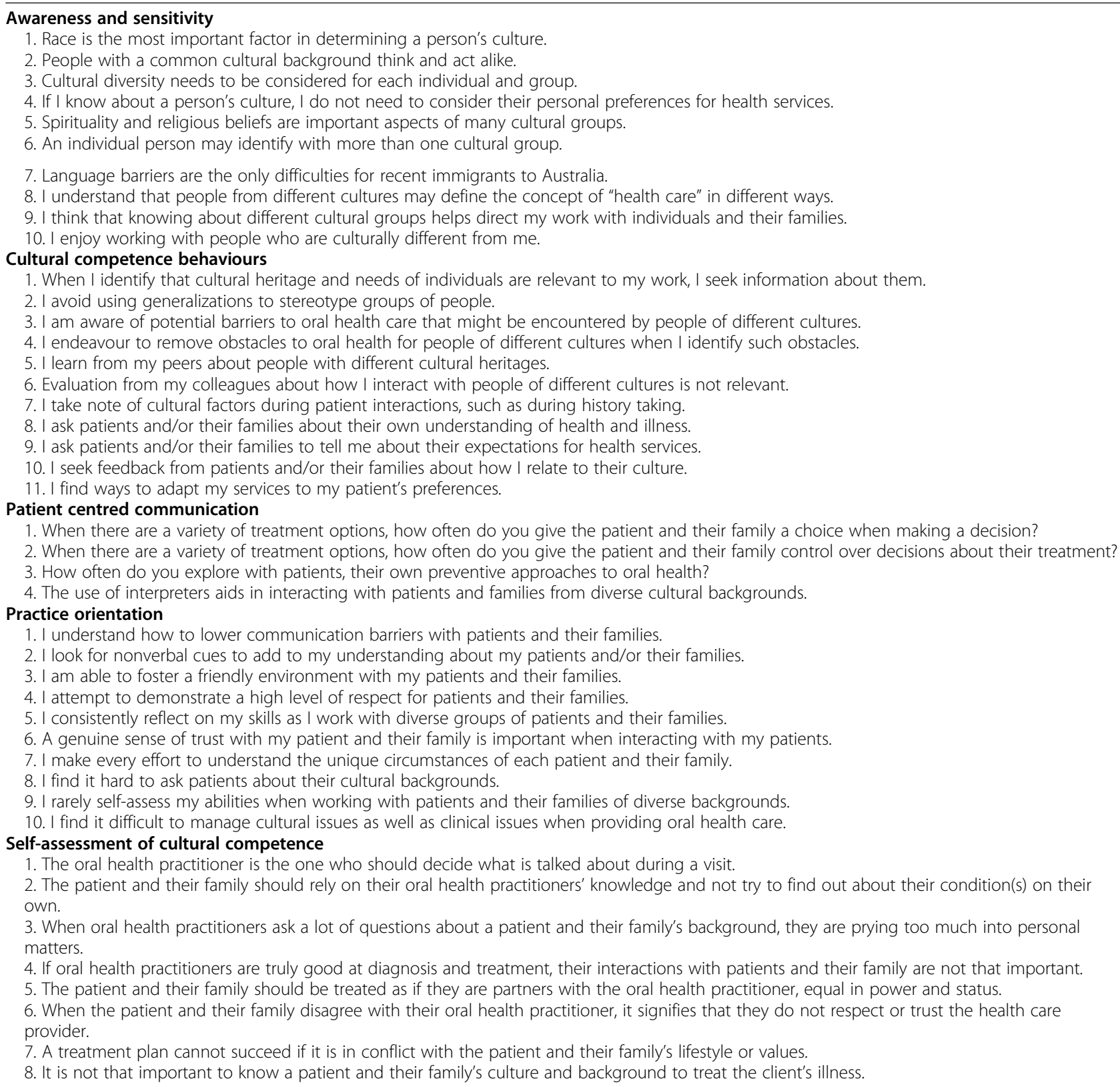

competence index was created by adding the responses across all of the five cultural competence items.

In addition to age, sex, year of study and course of study, and the ethnicity of the student sample was also collected. Ethnic self-identification was operationalized as the way one thinks of oneself [29], and was classified into five groups; "Australian"; "Other: [To be completed], but more Australian"; "Other: [To be completed] \& Australian equally"; "Australian, but more Other: [To be completed]"; and "Other: [To be completed]".

The generation of the student was determined by report of place of birth of the participant, their parents and grandparents. Participants were also asked about the language spoken at home. For those not born in Australia $(n=89)$, the length of time in Australia was also collected.

The statistical analysis provides basic descriptive information on the distribution of the socio-demographic, course and immigration variables. To investigate the patterns of responses for each cultural competence subscale and to determine whether there were similarities between cohorts, Kruskal-Wallis tests were conducted to compare responses for each of the individual items of the five value sub-scales due to the ordinal nature of the data. To test whether first year and final year students had the same pattern of means for each of the cultural 
competence subscales, Analysis of Variance (ANOVA) were employed. A significant ANOVA was followed by post-hoc comparisons using Tukey's tests. To test if any combination of the various socio-demographic course and immigration variables (e.g., age, sex, course of study, year, and ethnicity), provided a multivariate explanation of the cultural competence scores, a linear regression model was fitted using a stepwise selection method. When a probability value was 0.05 or smaller, the finding was considered to be statistically significant. Data manipulation and analyses were conducted using SPSS PC (Version 26.0).

\section{Results}

Two-hundred and thirteen students opted to participate in the study out of a possible 242, yielding an overall response rate of $88 \%$. The sample consisted of 27 first year and 25 third (i.e., final) year $\mathrm{BOH}$ students and 90 first year and 72 fourth (i.e., final) year DDS students. Participants in all four groups were primarily females. The exception was the DDS final year group, with the proportion of male respondents $54.2 \%$. The average age was 23.5 years (range 18-40 years) One-hundred and sixty-two participants were DDS students (76.1\%); and 51 were $\mathrm{BOH}$ students (23.9\%). One-hundred and sixteen were first year students (54.5\%) and 97 were final year students (55.5\%). Table 2 presents the distribution of students by year of study and by profession.

With regard to ethnic background, the largest group self-identified as "Australian" (35.7\%), and 31.0\% selfidentified as a combination of Australian and another ethnicity to some degree (See Table 2). The remaining participants identified solely with ethnic backgrounds other than "Australian" (32.9\%). Some participants did not specify their ethnicity (0.4\%). Participating students were mainly Australian born (52.6\%), of which a majority were first generation (74.6\%). The remaining participants were second generation (3.7\%) and third generation (21.7\%) Australians. Apart from Australia, students named another 26 countries of birth, most frequently mentioned were: Canada (7.4\%); China (7.4\%); and South Korea (6.3\%). Most students indicated speaking English consistently at home (61.5\%). Students who did not speak English consistently at home $(n=103)$ indicated speaking 21 other languages, mainly Mandarin (24.4\%), Cantonese (11.0\%), Korean (12.2\%), Arabic (9.7\%), or Vietnamese $(8.5 \%)$.

When comparing first year cohorts, statistically significant differences were found in two of the 24 items: Cultural competence behaviours ("When I identify that cultural heritage and needs of individuals are relevant to my work, I seek information about them"); and Selfassessment of cultural competence ("The patient and their family should rely on their oral health practitioners' knowledge and not try to find out about their condition(s) on their own"). In contrast, when comparing the two final year cohorts' responses, statistically significant differences were found in 9 out of 43 items $(p<0.05)$. This included, Awareness and sensitivity ("Cultural diversity needs to be considered for each individual and group"; "Spirituality and religious beliefs are important aspects of many cultural groups"; and "I think that knowing about different cultural groups helps direct my work with individuals and their families"); Cultural competence behaviours: ("I find ways to adapt my services to my patient's preferences"); Patient centred communication: "The use of interpreters aids in interacting with patients and families from diverse cultural backgrounds"); Practice orientation: ("I understand how to lower communication barriers with patients and their families"; "I look for nonverbal cues to add to my understanding about my patients and/or their families"; and "A genuine sense of trust with my patient and their family is important when interacting with my patients"); and Self-assessment of cultural competence: ("It is not that

Table 2 Participants socio-demographic characteristics and mean and standard deviation by course and year of study

\begin{tabular}{|c|c|c|c|c|c|}
\hline Cohort & $\begin{array}{l}\text { BOH1 } \\
\text { (n-26) }\end{array}$ & $\begin{array}{l}\mathrm{BOH} 3 \\
(\mathrm{n}-25) \\
\end{array}$ & $\begin{array}{l}\text { DDS1 } \\
(\mathrm{n}-90)\end{array}$ & $\begin{array}{l}\text { DDS4 } \\
(\mathrm{n}-72)\end{array}$ & $\begin{array}{l}\text { All } \\
(n-213)\end{array}$ \\
\hline Mean age (years) & 20.9 & 22.5 & 22.5 & 26.1 & 23.5 \\
\hline Male (\%) & 23.1 & 36.0 & 50.0 & 54.2 & 46.5 \\
\hline Australia- born (\%) & 57.7 & 72.0 & 45.6 & 50.0 & 51.6 \\
\hline \multicolumn{6}{|l|}{ Ethnic identification (\%) } \\
\hline Australian & 38.5 & 52.0 & 26.7 & 40.3 & 35.7 \\
\hline Ethnic group but more Australian & 7.7 & 12.0 & 11.1 & 8.3 & 9.9 \\
\hline Ethnic group Australian equally & 15.4 & 8.0 & 13.3 & 5.6 & 10.3 \\
\hline Ethnic group but less Australian & 3.8 & 20.0 & 7.8 & 13.9 & 10.8 \\
\hline Ethnic group & 34.6 & 8.0 & 41.1 & 30.6 & 32.9 \\
\hline
\end{tabular}

$\mathrm{BOH1}$ First year Bachelor of Oral Health, $\mathrm{BOH} 3$ Final year Bachelor of Oral Health, DDS1 First year Doctor of Dental Surgery, DDS4 Final year Doctor of Dental Surgery 
important to know a patient and their family's culture and background to treat the client's illness") (Table 1).

As there were a few participants who did not complete the full questionnaire, the analysis that follows only includes those students with no missing answers $(n=187$; 27 first year and 23 third year $\mathrm{BOH}$ students and 89 first year and 48 fourth year DDS students). Means and standard deviation of the cultural competence subscales scores by course of study are presented in Table 3. As expected, when first and final year scores were compared, they were statistically significantly different $(p<$ 0.001). However, there were not statistically different scores between the first-year student cohorts (i.e., BOH1 compared with DDS1). The exception was self-assessed cultural competence where $\mathrm{BOH} 1$ scored higher than DDS1 (1.56 vs. $1.24 ; p<0.05)$. On the other hand, when scores from final year DDS were compared to final year $\mathrm{BOH}$, statistically significant differences were found in the responses to the Self-assessed cultural competence $(p<0.01)$; and the Cultural competence behaviours $(\mathrm{p}<$ 0.05 ) subscales (Table 3 ).

The overall cultural competence scores ranged from 1.0 to 41.0, with a mean value of 20.0 (s.d. 8.9), with significant differences by cohort $(p<0.001)$. While BOH1 and DDS1 students' scores were not statistically significant [13.7 (s.d. 2.2), and 13.7 (s.d. 2.7), respectively], BOH3 and DDS4 students' scores [33.0 (s.d. 3.7), and 29.3 (s.d. 5.0), respectively] were statistically significantly, with BOH3 having higher scores than DDS4 $(\mathrm{p}<0.01)$. Additionally, cultural competence scores from first year students were compared to final years' scores by course with scores corrected for questions omitted. In both courses, scores were statistically significantly higher in the final year compared to first year (13.8 vs. $19.2 ; p<$ 0.0001 for $\mathrm{BOH}$ and 13.7 vs. $16.8 ; \mathrm{p}<0.001$ for DDS).

Statistically significant scores in the overall cultural competence were also found by country of birth, where Australia-born participants scored higher than those born-overseas ( 21.44 vs. $18.61 ; p<0.05)$, and by ethnic self-identification, where those who self-identified as
"Australian" had higher scores than those with "Other" self-identifications $(21.78$ vs. $17.02 ; \mathrm{p}<0.05)$. No significant differences were present by age, years in Australia, sex, generation, or language spoken at home.

To better understand the variance in the overall cultural competence score, seven socio-demographic and immigration variables (age, sex, self-reported ethnicity, generation, language spoken at home, country of birth and course-year), were entered into a multiple linear regression model. Three variables (i.e., sex, self-reported ethnicity, course and year of study) remained significant in the final model $[\mathrm{F}(5,182)=233.48 p<0.0001]$. The resulting model indicated that, after controlling for other independent variables in the model, those who had the highest cultural competence score were female, who self-identified as "Australian", and who were in the final $\mathrm{BOH}$ year. The variance accounted for, using the full model, was $86.3 \%$ (adjusted $R^{2}=0.863$ ) (See Table 4).

\section{Discussion}

Dental students need to acquire the ability to effectively interact with and provide holistic, person-centred care for patients from diverse backgrounds, and also to understand the social, structural and cultural influences on oral health behaviour that are common in a multicultural society such as Australia. They need to develop attitudes that accommodate difference as well as the ability to communicate effectively with patients across cultures. Findings from this study suggest that dentistry and oral health students exhibited dissimilar levels of self-perceived cultural competence at different stages of their education and also within different courses. Overall results indicate that, at the end of their professional training, students' exposure to professional education and socialization would have resulted in an overall improved score on the cultural competence survey. Australian Dental Council requirements include students' acquisition of core cultural competency skills to provide culturally safe oral health care, at the end of their professional training [15]. Of course, further assessments of

Table 3 Participants mean and standard deviation in Cultural Competence scale and subscales by course and year of study

\begin{tabular}{lllll}
\hline Scale & $\begin{array}{l}\text { BOH1 } \\
(\mathbf{n}-\mathbf{2 7})\end{array}$ & $\begin{array}{l}\text { BOH3 } \\
(\mathbf{n}-\mathbf{2 3})\end{array}$ & $\begin{array}{l}\text { DDS1 } \\
(\mathbf{n}-\mathbf{8 9})\end{array}$ & $\begin{array}{l}\text { DDS4 } \\
(\mathbf{n}-\mathbf{4 8})\end{array}$ \\
\hline Awareness and sensitivity & $8.13(1.21)$ & $8.13(1.21)$ & $7.82(1.64)$ & $7.56(1.35)$ \\
Cultural competence behaviours & $4.35(1.33)$ & $8.17(2.34)$ & $4.65(1.28)$ & $6.88(2.37)$ \\
Patient centred communication & - & $3.65(0.57)$ & - & $3.40(1.01)$ \\
Practice orientation & - & $6.86(1.06)$ & - & $6.41(1.38)$ \\
Self-assessed cultural competence & $1.56(0.70)$ & $6.21(1.28)$ & $1.24(0.71)$ & $5.06(1.95)$ \\
Overall Cultural competence & - & $33.04(3.72)$ & - & $13.31(5.01)$ \\
Overall Cultural competence (adjusted for first years) & $13.74(2.19)$ & $19.22(2.58)$ & $13.71(2.65)$ & $16.79(3.39)$ \\
\hline
\end{tabular}

$\mathrm{BOH} 1$ First year Bachelor of Oral Health, $\mathrm{BOH} 3$ Final year Bachelor of Oral Health, DDS1 First year Doctor of Dental Surgery, DDS4 Final year Doctor of Dental Surgery 
Table 4 Final multivariate model identifying the Cultural competence Score score

\begin{tabular}{|c|c|c|}
\hline Independent variable & $\begin{array}{l}\text { Multiple regression coefficient } B \\
\text { (Std. Error) }\end{array}$ & $p$ \\
\hline Female $(\mathrm{No}=0 ; \mathrm{Yes}=1)$ & $1.70(0.50)$ & 0.001 \\
\hline Self-identification (Australia: $\mathrm{No}=0 ; \mathrm{Yes}=1$ ) & $1.63(0.49)$ & 0.001 \\
\hline DDS1 student $(\mathrm{No}=0 ; \mathrm{Yes}=1)$ & $-15.42(0.60)$ & 0.0001 \\
\hline $\mathrm{BOH} 1$ student $(\mathrm{No}=0 ; \mathrm{Yes}=1)$ & $-15.90(0.81)$ & 0.0001 \\
\hline $\mathrm{BOH} 3$ student $(\mathrm{No}=0 ; \mathrm{Yes}=1)$ & $3.43(0.85)$ & 0.0001 \\
\hline $\begin{array}{l}\text { Intercept } \\
\text { Adjusted } r^{2}=0.863\end{array}$ & $27.64(0.60)$ & 0.0001 \\
\hline
\end{tabular}

students' cultural competence need to be conducted using multiple approaches to feel confident that learning outcomes in cultural competence and safety have been met.

Furthermore, multivariate results indicate that final year $\mathrm{BOH}$ students scored significantly higher in cultural competence, when compared to final year DDS students. These students were from two different courses, one of which is an undergraduate degree (i.e., $\mathrm{BOH}$ ) whilst the other is a graduate degree (i.e., DDS). These courses also lead students into different dental professions with a differing scope of practice. Therefore, despite their exposure to patients being largely in the same clinics with patients drawn from the same pools, their clinical experiences between courses varied. In a review of cultural competence content in the DDS and $\mathrm{BOH}$ curricula, the DDS course showed less time devoted to formal teaching of this content compared to $\mathrm{BOH}$ courses $[6,21]$.

It has also been identified that cultural competency skills can be developed indirectly via clinical placements and via interactive learning programs $[5,22]$. In addition, a detailed assessment of the extent of cultural competence education, which took into consideration all written and current documentations of the curriculum at the UoMDS, as well as the number of formal contact hours and credit points allocated $[6,18]$, reported that the $\mathrm{BOH}$ course assigned fifty-four hours to the teaching of cultural competence content throughout the first 2 years of the course [21]. Whereas the DDS course allocated forty hours confined to the first year of the course [21]. However, that assessment was done just counting documented hours and some other content (such as role modelling, clinical mentoring and student reflective practice) may not be visible in the curriculum of both courses using this method.

Other reports indicated that the teaching techniques used might have been ineffective. Strauss and collaborators [20] observed that most North American dental schools favoured less effective and passive learning techniques such as lectures. This inadequacy was also reported by dental students and graduates who indicated that inclusion of cultural awareness was important in the dental curricula, but that the current curricula needed revising to develop their skills in interacting with patients [7]. In another study, Saleh and collaborators [19] found that the time assigned to complete course tasks and the lack of knowledgeable educators on the topic were major contributing factors. This is further supported by the inconsistency of the cultural competence education between dental curricula of various schools in Australia and New Zealand, thus indicating a need for a standard framework for cultural competency education [9].

Clinical placements offer important opportunities for dental students to develop cultural competence skills first-hand via demonstration of patient management by experienced dental practitioners, having direct interactions with patients and their families, as well as interaction with clinical supervisors that are observing them and are able to give them further insights [5].It has been reported that students interacting with patients from diverse cultural groups and reflecting upon these experiences, assists in refining students' existing beliefs about particular cultural groups preventing stereotyping [30].

The development of cultural competence and safety relies on good role modelling and attention from supervisors to cultural competence skills development of students, reflective practice and active assessment of knowledge, attitudes and practice skills [27]. Emphasis should also be placed on providing students with opportunities to reflect on their own and others' cultural values to help them understand the meaning of new experiences and reflect over how these relate to their current experiences [30].

Continuous teaching with a gradual increase in complexity has been considered the most effective method of teaching cultural competence, thus exposure to these concepts in previous undergraduate study may also contribute to differences between the courses [31, 32]. Interestingly, a study investigating social and cultural teaching of medical students concluded that the teaching made little to no difference when students began clinical rotations [33]. The medical students explained that despite an interest in the content, the goal of clinical 
practice was to treat everyone neutrally, as if they were cultureless [33]. Similarly, clinical supervisors at the UoMDS commented that DDS students appeared to focus on completing treatment rather than building rapport with patients [5]. It was noted that this may be a result of students being graded mostly on their technical skills, rather than their cultural or communication skills $[5,34]$.

It is also important to consider, in addition to the effects of course curriculum, students' sociodemographic, immigration and cultural backgrounds, as these factors may affect an individual's perceived cultural competency level irrespective of their degree of clinical experience. In this regard, it is possible that sociodemographic background has a bearing on an individual's perceived cultural competence, as these factors influence their beliefs, expectations and interpretation of their own experiences. Such factors include how the participants identified culturally and whether they were linguistically diverse. The participants' country of birth or family history of immigration, that is, whether they were overseas born or are first, second or third generation Australian, may further influence how they interpret competence and how culturally competent they perceive themselves to be. However, despite the variation in cultural identity among respondents, a consistent pattern of responses across the scales was evident when comparing Australian and overseas born participants. This may be explained by the idea that country of birth alone may not be an accurate descriptor of cultural background, as there are many other factors such as level of acculturation, self-reported ethnicity and languages spoken, life experiences and socio-economic status that contribute to one's culture [35-37].

The present analysis of the cultural competence scores indicated that those born overseas tended to have lower scores. Moreover, the multivariate analysis indicated that those who self-identified as "Australian", scored higher than those who did not. These findings may reflect the culturally located nature of the survey, or the socialisation inherent in Australian dental curricula. Furthermore, overseas born students may also not recognise that their ability to traverse their own and Australian cultures represents an element of competence. This also highlights the notion that there might be a distinction between having a culturally and linguistically diverse background (CALD) and being culturally competent. It cannot be assumed that a CALD individual possesses cultural competence because of birthplace, cultural background, or the languages that he or she speaks [38], but rather that this is developed from tolerance, empathy and understanding of cross-cultural issues. This concept was also challenged by Mariño and his collaborators, who found that dentistry students reported cultural values that were largely similar regardless of their backgrounds [39].

Although this study provides valuable insights into the cultural competence acquisition process among dentistry and oral health students, it is not without limitations. The most obvious limitation was the cross-sectional nature of this study, which precludes a strong conclusion about increasing cultural competence with exposure to dental professional education, or the use of year of study as a good proxy for years of exposure to professional socialization. This introduces the influence of variation between cohorts in terms of socio- demographics, personalities, experiences and other factors. As such, it may be that some significant differences have resulted from this. Additionally, the study relied on self-reported data, which may not be an accurate reflection of the relationship between self-perceived and actual culturally competent practice [7, 40]. Another concern is that participants were all students at the UoMDS. As a result, conclusions drawn from this study may not be representative of the cultural competency of all Australian dental profession students, or students at dental schools elsewhere [41]. However, considering these limitations, we believe that the current approach was adequate given the exploratory nature of the study.

\section{Conclusions}

The findings of this study demonstrate that there is a significant difference in self-reported cultural competence as students progressed through their dental training. Students tended to exhibit increasing levels of selfreported cultural competence as they progressed in their studies, but also depending on their course.

Future research should involve the collection of longitudinal data to explore how cultural competence changes over time. Additionally, exploring embedded curriculum content, unconscious bias, reflective practice and role modelling, with explicitly aligned learning objectives and assessments, will enhance future cultural competence curricula in dental and oral health programmes. Collaboration with other dental schools in Australia and overseas would be beneficial in confirming the present results and understanding the influence of cultural competence education on dental students as future dental practitioners.

\section{Abbreviations}

ADC: Australian Dental Council; ANOVA: Analysis of Variance; $\mathrm{BOH}$ : Bachelor of Oral Health; $\mathrm{BOH}$ 1: First year Bachelor of Oral Health; $\mathrm{BOH}$ : Final year Bachelor of Oral Health; CALD: Culturally and linguistically diverse; DDS: Doctor of Dental Surgery; DDS1: First year Doctor of Dental Surgery; DDS4: Final year Doctor of Dental Surgery; HPCCI: Healthcare Provider Cultural Competence Instrument; UoMDS: University of Melbourne Dental School 


\section{Acknowledgements}

The authors would like to acknowledge Dr. Joshua Schwarz for kindly providing permission to utilise the $\mathrm{HPCCl}$ in this study, as well as all students who participated in the conduct of this study.

\section{Authors' contributions}

RM: Participated in the conception and design of the study, acquisition of data, analysis, and interpretation of data; as well as drafting of the manuscript and its critical revision, and approval of the final version. JS: Participated in the conception and design of the study, acquisition of data, analysis, and interpretation of data; as well as drafting of the manuscript and its critical revision, and approval of the final version. ET: Participated in the conception and design of the study, acquisition of data, analysis and interpretation of data; as well as critical revision, and approval of the final version. MT: Participated in the conception and design of the study, acquisition of data, analysis, and interpretation of data; as well as critical revision, and approval of the final version. EM: Participated in the conception and design of the study, and interpretation of data; as well as critical revision, and approval of the final version. VT: Participated in the conception and design of the study, acquisition of data, analysis, and interpretation of data; as well as critical revision, and approval of the final version. PT: Participated in the conception and design of the study, acquisition of data, analysis, and interpretation of data; as well as critical revision, and approval of the final version. RT: Participated in the conception and design of the study, acquisition of data, analysis, and interpretation of data; as well as critical revision, and approval of the final version.

\section{Funding}

Not applicable.

\section{Availability of data and materials}

Ethics approval was granted on the basis that only researchers involved in the study and could access the de-identified data. The minimum retention period is 5 years from publication. Supporting documents are available upon request to the corresponding author.

\section{Declarations}

\section{Ethics approval and consent to participate}

Formal ethical approval was obtained from the University of Melbourne Human Research Ethics Committee (ID:1749059.2). All methods were conducted following the approved methodology and in accordance with the relevant guidelines and regulations. All participants consented to participate in this study. Potential participants received written information that reception of completed surveys was assumed as consent for participation in the study.

\section{Consent for publication}

\section{Not applicable.}

\section{Competing interests}

The authors declare that they have no competing interest. Rodrigo Mariño is a Section Editor for BMC Oral Health.

\section{Received: 9 August 2020 Accepted: 2 March 2021}

Published online: 12 March 2021

\section{References}

1. Statistics AB of. 3412.0 - Migration, Australia, 2014-15 [Internet]. Australian Bureau of Statistics. 2016 [cited 2016 Aug 13]. Available from: http://www.a bs.gov.au/ausstats/abs@.nsf/mf/3412.0/.

2. De Lew N, Weinick RM. An overview: eliminating racial, ethnic, and SES disparities in health care. Health Care Financ Rev. 2000;21:1-7.

3. Aleksejuniene J, Zed C, Mariño R. Self-perceptions of cultural competence among dental students and recent graduates. J Dent Educ. 2014;78:389400.

4. Clifford A, McCalman J, Bainbridge R, et al. Interventions to improve cultural competency in health care for indigenous peoples of Australia, New Zealand, Canada and the USA: a systematic review. International J Qual Health Care. 2015;27:89-98.
5. Mariño R, Ghanim A, Morgan M, et al. Cultural competency and communication skills of dental students: clinical supervisors' perceptions. Eur J Dent Educ. 2017;21:e101-e8.

6. Mariño R, Hawthorne L, Morgan M, et al. Transcultural skills content in a dental curriculum: a comparative study. Eur J Dent Educ. 2012;16:e33-40.

7. Mariño R, Morgan M, Hawthorne L, et al. Self-reported cultural skills from dental students and graduates from Melbourne, Australia. Eur J Dent Educ. 2013:17:e159-65.

8. Mariño R, Morgan M, Hopcraft M. Transcultural dental training: addressing the oral health care needs of people from culturally diverse backgrounds. Community Dent Oral Epidemiol. 2012;40(Suppl 2):134-40.

9. Nicholson SL, Hayes MJ, Taylor JA. Cultural competency education in academic dental institutions in Australia and New Zealand: a survey study. J Dent Educ. 2016;80:966-74.

10. Kwan S, Mariño R, Kiyak HA, Minichiello V, MacEntee M. Ethno-cultural diversity. In: MacEntee M, Chalmers J, Müller F, Wyatt C, editors. Oral Healthcare for Frail Elders. Ames: Blackwell Publishing. Limited; 2011. p. 237-54

11. Butani Y, Weintraub JA, Barker JC. Oral health-related cultural beliefs for four racial/ethnic groups: assessment of the literature. BMC Oral Health. 2008;8:26.

12. Alrqiq HM, Scott TE, Mascarenhas AK. Evaluating a cultural competency curriculum: changes in dental Students' perceived awareness, knowledge, and skills. J Dent Educ. 2015;79:1009-15.

13. Betancourt JR, Green AR, Carrillo JE, et al. Defining cultural competence: a practical framework for addressing racial/ethnic disparities in health and health care. Public Health Rep. 2003;118:293-302.

14. Dental Board of Australia. Code of Conduct: For registered health practitioners [Internet]. Dental Board of Australia; 2014 Mar. Available from: http://www.dentalboard.gov.au/Codes-Guidelines/Policies-Codes-Guidelines/ Code-of-conduct.aspx.

15. Australian Dental Council/Dental Council (New Zealand). Accreditation Standards for Dental Practitioner Programs [Internet]. Australian Dental Council; 2021 Dec. Available from: https://www.adc.org.au/sites/default/files/ Media_Libraries/ADC_DCNZ_Accreditation_Standards_FINAL.pdf.

16. Univeristy of Melbourne. Beyond 2018; A strategic plan. Faculty of medicine, Dentistry and Health Sciences 2017. Available from: https://mdhs.unimelb. edu.au/_data/assets/pdf_file/0011/2465084/Beyond2018.pdf

17. Schwarz JL, Witte R, Sellers SL, Luzadis RA, Weiner JL, Domingo-Snyder E, Page JE Jr. Development and psychometric assessment of the healthcare provider cultural competence instrument. Inquiry. 2015;52: 0046958015583696. https://doi.org/10.1177/0046958015583696.

18. Rowland ML, Bean CY, Casamassimo PS. A snapshot of cultural competency education in US dental schools. J Dent Educ. 2006;70:982-90.

19. Saleh L, Kuthy RA, Chalkley $Y$, et al. An assessment of cross-cultural education in U.S. dental schools. J Dent Educ. 2006;70:610-23.

20. Strauss RP, Stein MB, Edwards J, et al. The impact of community-based dental education on students. J Dent Educ. 2010;74(10 Suppl):S42-55.

21. Mariño RJ, Ghanim A, Barrow SL, et al. Cultural competence skills in a dental curriculum: a review. Eur J Dent Educ. 2018;22:e94-e100.

22. Wagner JA, Redford-Badwal D. Dental students' beliefs about culture in patient care: self-reported knowledge and importance. J Dent Educ. 2008; 72:571-6.

23. Gundersen D, Bhagavatula P, Pruszynski JE, et al. Dental students' perceptions of self-efficacy and cultural competence with school-based programs. J Dent Educ. 2012;76:1175-82.

24. Forsyth C, Short S, Gilroy J, Tennant M, Irving M. An indigenous cultural competence model for dentistry education. Br Dent J. 2020;228:719-25.

25. Faculty of Medicine, Dentistry and health Sciences, The University of Melbourne- Indigenous Development- Five Year Action Plan (2018). Available from: https://mdhs.unimelb.edu.au/beyond2018/indigenousdevelopment/indigenous-development-action-plan.

26. University of Melbourne. Advancing Melbourne 2030. (2020) Available from: https://about.unimelb.edu.au/strategy/advancing-melbourne

27. Forsyth C, Irving M, Tennant M, Short S, Gilroy J. Teaching cultural competence in dental education: a systematic review and exploration of implications for indigenous populations in Australia. J Dent Educ. 2016;81: 956-68

28. Waltz CF, Strickband OL, Lenz ER. Measurement in nursing research. 2nd ed. Philadelphia: FA Davies Co; 1991. p. 181.

29. Berry JW, Trimble J, Olmedo E. Assessment of acculturation. In: Lonner WJ, Berry JW, editors. Fields methods in cross-cultural research. Beverly Hills: SAGE Publication Ltd.; 1986. p. 291-349. 
30. Forsyth C, Irving M, Short S, Tennant M. Students don't know what they don't know: dentistry students' perspectives on indigenous cultural competence curricula. J Dent Educ. 2019;83:679-86.

31. Hannah A, Millichamp CJ, Ayers KM. A communication skills course for undergraduate dental students. J Dent Educ. 2004;68(9):970-7.

32. Yoshida T, Milgrom P, Coldwell S. How do U.S. and Canadian dental schools teach interpersonal communication skills? J Dent Educ. 2002;66(11):1281-8.

33. Beagan BL. Teaching social and cultural awareness to medical students: "it's all very nice to talk about it in theory, but ultimately it makes no difference". Acad Med. 2003;78(6):605-14.

34. Forsyth C, Irving M, Short S, Tennant M. Strengthening indigenous cultural competence in dentistry and oral health education: academic perspectives Eur J Dent Educ. 2019;23:e37-44.

35. Sam DL, Berry JW. Acculturation: when individuals and groups of different cultural backgrounds meet. Perspect Psychol Sci. 2010:5:472-81.

36. Mariño R, Stuart GW, Minas H. Acculturation of values and behaviour: a study of Vietnamese immigrants. Measure Eval Counsel Dev. 2000;33:21-41.

37. Stronks K, Kulu-Glasgow I, Agyemang C. The utility of 'country of birth' for the classification of ethnic groups in health research: the Dutch experience. Ethn Health. 2009;14:255-69.

38. Victorian Government Department of Health. Review of current cultural and linguistic diversity and cultural competence reporting requirements, minimum standards and benchmarks for Victoria health services project. Melbourne: Victoria Univeristy; 2009

39. Mariño R, Stuart G, Morgan M, Winning T, Thompson M. Cultural consistency in Australian dental students from different ethnic backgrounds. J Dent Educ. 2004;11:1178-84.

40. Seeleman C, Hermans J, Lamkaddem M, et al. A students' survey of cultural competence as a basis for identifying gaps in the medical curriculum. BMC Med Educ. 2014;14:216.

41. Rubin RW, Rustveld LO, Weyant RJ, et al. Exploring dental students' perceptions of cultural competence and social responsibility. J Dent Educ. 2008:72:1114-21.

\section{Publisher's Note}

Springer Nature remains neutral with regard to jurisdictional claims in published maps and institutional affiliations.

Ready to submit your research? Choose BMC and benefit from:

- fast, convenient online submission

- thorough peer review by experienced researchers in your field

- rapid publication on acceptance

- support for research data, including large and complex data types

- gold Open Access which fosters wider collaboration and increased citations

- maximum visibility for your research: over $100 \mathrm{M}$ website views per year

At $\mathrm{BMC}$, research is always in progress.

Learn more biomedcentral.com/submissions 